\title{
Changing the Landscape of Stroke in Egypt
}

\author{
Hany Aref Magd Zakaria Hossam Shokri Tamer Roushdy \\ Ahmed El Basiouny Nevine El Nahas
}

Neurology Department, Ain Shams University, Cairo, Egypt

\section{Keywords}

Egypt - Stroke · Low- and middle-income countries .

Thrombolysis · Recombinant tissue plasminogen activator

\begin{abstract}
Egypt, a low-middle-income country, is the most populated nation in the Middle East with a high overall crude prevalence rate of stroke (963/100,000 inhabitants), accounting for $6.4 \%$ of all deaths. In this article, we discuss how, through a corrective plan, we could change the landscape of stroke services in Egypt, in a relatively short time, raising thrombolysis rate from $<1 \%$ to $12.3 \%$, with shortening of door-toneedle time. We could build a database that now exceeds 5,000 patients, our centers received international accreditation and several awards, and we developed tele-stroke service.

(c) 2021 The Author(s).

Published by S. Karger AG, Basel
\end{abstract}

Egypt, a low-middle-income country, is the most populated nation in the Middle East with 102,327,319 inhabitants on September 7, 2021 [1] and an annual rate of increase of population of $1.9 \%$ [2]. And despite that in the past 4 decades mortality due to stroke has fallen by $42 \%$ in high-income countries, yet on the contrary, it has risen

karger@karger.com www.karger.com/cee

Karger $\stackrel{\text { ' }}{5}$

GOPEN ACCESS
C 2021 The Author(s).

Published by S. Karger AG, Basel

This is an Open Access article licensed under the Creative Commons Attribution-NonCommercial-4.0 International License (CC BY-NC) (http://www.karger.com/Services/OpenAccessLicense), applicable to the online version of the article only. Usage and distribution for commercial purposes requires written permission. by more than $100 \%$ and is expected to further increase in low- and middle-income countries in the coming years [3]. In Egypt, the overall crude prevalence rate of stroke is high (963/100,000 inhabitants), and the incidence of stroke annually is approximately $150,000-210,000$. The official national statistics indicate that diseases of the circulatory system, including stroke, are the primary causes of death in Egypt, where stroke accounts for $6.4 \%$ of all deaths and ranks third after cardiovascular and gastrointestinal diseases. Although the number of deaths attributed to stroke has declined in many countries, in Egypt, it was relatively unchanged over the past 10 years $[4,5]$. In addition, although the percent of population aged above 50 is only $12.7 \%$ [6], yet there is a relatively high proportion of stroke in young reaching $20.5 \%$ in some areas as shown by a previous study. This might explain the high prevalence and incidence of stroke among Egyptians, despite the low percent of aged population [7].

The situation of stroke practice in Egypt can be divided into 2 phases: before and after 2015. The first dedicated stroke unit in Egypt was established in 1991 at Ain Shams University Specialized Hospital (ASU). It used to provide a protocol-led stroke service to more than 600 patients annually. The second stroke unit was established in Cairo University Hospitals in 1996. However, until 2015, stroke service could be depicted as having efficient 


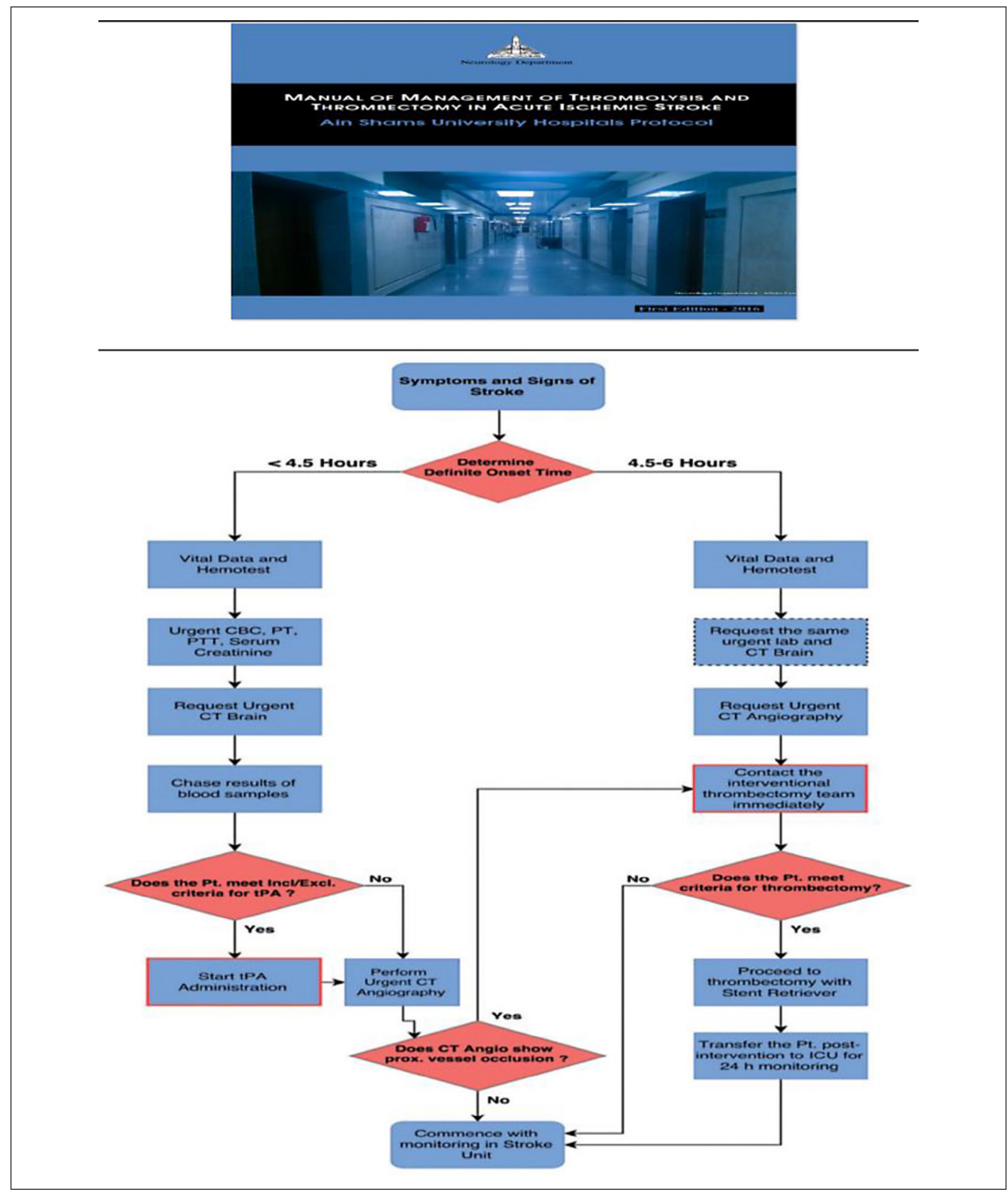

Fig. 1. Algorithm illustrating the management of acute ischemic stroke applied in Ain Shams University stroke units and adopted by the stroke chapter of the Egyptian Society of Neurology, Psychiatry, and Neurosurgery. 
Table 1. Comparison between stroke patients' numbers before and after corrective action plan

\begin{tabular}{lll}
\hline & First study & Second study \\
\hline Admitted patients, $N$ & 269 & 284 \\
Eligible patients for acute treatment, $N$ & 53 & 37 \\
Patients who received acute treatment, $N$ & 7 & 35 \\
Total ischemic stroke patients who received acute reperfusion treatment, $\%$ & 2.7 & 12.3 \\
Eligible patients who received acute treatment, $\%$ & 13.2 & 94.6 \\
\hline
\end{tabular}

From Zakaria et al. [5].

physicians with a long history of local research but limited international publications and deficient documentation with nearly no stroke database and less than ten stroke units across Egypt. Recombinant tissue plasminogen activator was used in $<1 \%$ of stroke cases with no reimbursement from the Ministry of Health $(\mathrm{MOH})$ for this costly emergency treatment [8].

The history of stroke services in Egypt literally changed in 2014, when the stroke unit in ASU, a public university hospital, was established. The stroke team at ASU started a research on the obstacles for prehospital and in-hospital proper acute stroke management. The causes of prehospital and in-hospital delay were reported by this study [5].

Accordingly, an action plan was established to improve the in-hospital delay, composed of a training program for reperfusion therapies in ischemic stroke, conducted jointly with the radiology department, as a part of the training program for neurology residents. After fulfilling this training, the residents were provided with a manual of guidelines for reperfusion therapies for acute ischemic stroke. The algorithm illustrating the management of acute ischemic stroke applied in the stroke units is shown in Figure 1. Every eligible patient has to be reported to a senior staff member on call for consultation [8].

Concomitant with this program, fund raising was started in the ASU stroke unit to make alteplase available through donations. By these measures, the 2 main obstacles for in-hospital delay were overcome. This resulted in a dramatic change in performance [5]. In a 6-month period (January to June 2016), a significant increase in the thrombolysis rate has been achieved. Of 284 patients admitted with acute ischemic stroke, 37 were eligible for thrombolysis, of whom 35 underwent thrombolysis (94.3\%), representing $12.3 \%$ of the total ischemic stroke admissions (Table 1) [5].

In June 2016, as a result of this strong advocacy case, the $\mathrm{MOH}$ acknowledged the importance of improving acute stroke management in Egypt and approved the reimbursement of intravenous thrombolysis. This was the spark plug that ignited the drive to change stroke services in Egypt, with all other Egyptian universities attempting to follow the same path as that of ASU [8].

In late 2016, Cairo University launched a stroke unit with 32 beds, the largest in the region. From then onward, the number of stroke units started to increase across Egypt, reaching 95 by the beginning of 2020 [8].

In the same year (2016), the Angels initiative was launched, and Egypt cooperated with great enthusiasm. We started to build our stroke database by registering in the SITS registry, and in 2019, the input of Egyptian stroke centers reached 5,753 patients [9]. Training and continuous education programs were initiated in cooperation with the Angels initiative to improve existing stroke units and open new ones. This paved the way for winning Angels awards and accreditation [8].

In 2017, the MOH established the National Stroke Committee and adopted the SITS as the Egyptian stroke national registry. Almost simultaneously, the stroke chapter of the Egyptian Society of Neurology, Psychiatry, and Neurosurgery started to be extremely active with representatives from all university stroke units across Egypt. The chapter approved the ASU manual of acute stroke management to be the standard protocol for Egypt. Moreover, with the cooperation of the Ministry of Higher Education, the decision was made to transform the university's stroke units into comprehensive stroke units acting as hubs for satellite primary and stroke-ready units, which are under the umbrella of the $\mathrm{MOH}$ [8].

As for thrombectomy, in 2018, the $\mathrm{MOH}$ agreed to reimburse it in response to the tangible progress in stroke service. As a result, the frequency of thrombectomies started to increase from 17 cases in 2016 to 172 cases in 2019. In 2018, a tele-stroke unit was started in Egypt in ASU stroke centers and was linked to the Kafr El Sheikh General Hospital stroke unit in the delta region $(190 \mathrm{~km}$ 


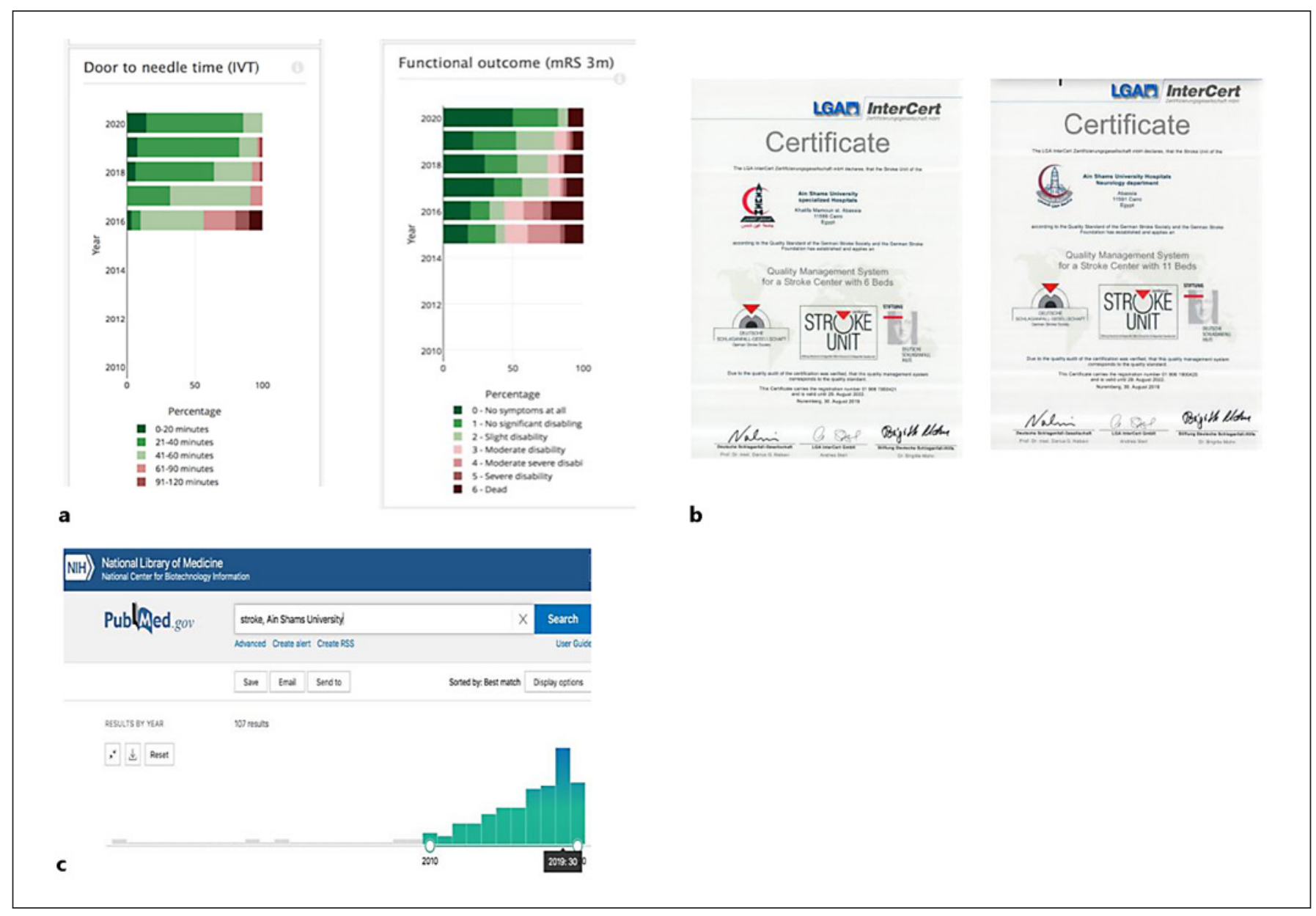

Fig. 2. a Door-to-needle time progressively decreased and functional outcome increased over the past 5 years in 2 stroke centers of Ain Shams University Hospitals (ASUH). b Certificates of accreditation of Ain Shams University stroke centers. c Increase in stroke publications in Ain Shams University over 9 years.

north of Cairo), aiming to provide online expert consultation to neurologists in remote hospitals for stroke management and, consequently, introducing tele-stroke services in Egypt [8].

The performance of the ASU stroke centers, where the stroke initiative started, showed a progressive increase in the rate of acute stroke therapy, whether thrombolysis or thrombectomy. This was accompanied by a steadily decreasing door-to-needle time and improving functional outcome of patients (Fig. 2a).

Consequently, the 2 stroke units of ASU were accredited as internationally certified stroke centers in August 2019 (Fig. 2b), being the only internationally accredited stroke centers in Egypt. Additionally, a couple of centers from Egypt received European Stroke Organization (ESO) Angels awards and World Stroke Organization (WSO)
Angels awards [10]. Regarding the output of international publications from ASU in stroke research, an analysis in PubMed has shown an exponential increase from 3 publications in 2010 to 30 publications in 2019 (Fig. 2c).

In conclusion, we have shown that with a strategic plan and its consequent implementation, stroke care can be significantly improved in a low-to-middle-income country in a relatively short period. However, we still have a long road ahead. To achieve a state-of-the-art stroke service, at least 500 stroke units are needed to provide stroke services to the whole population. Tele-stroke service with a hub-and-spoke model needs to be expanded to cover all distant centers. Moreover, extensive work is needed to raise public and primary care physicians' awareness on stroke symptoms, and fast treatment in stroke-ready hospitals is crucial. 


\section{Conflict of Interest Statement}

The authors have no conflicts of interest to declare.

\section{Funding Sources}

No funding was received for this manuscript.

\section{Author Contributions}

All the authors have the same contribution in all process of the manuscript preparation including designing and conceptualizing the study, analyzing the data, and drafting and revising the manuscript for intellectual content.

\section{References}

1 "No title". Available from: https://www.capmas.gov.eg/?lang=2.

2 "The World Bank," [Online]. Available from: https: //data.worldbank.org/indicator/SP. POP.GROW? locations=EG.

3 Mensah GA, Norrving B, Feigin VL. The global burden of stroke. Neuroepidemiology. 2015;45(3):143-5.

4 GBD 2016 Causes of Death Collaborators. Global, regional, and national age-sex specific mortality for 264 causes of death, 1980-2016: a systematic analysis for the Global Burden of Disease Study 2016. Lancet. 2017 Sep 16; 390(10100):1151-210.
5 Zakaria MF, Aref H, Abd ElNasser A, Fahmy N, Tork MA, Fouad MM, et al. Egyptian experience in increasing utilization of reperfusion therapies in acute ischemic stroke. Int J Stroke. 2018;13(5):525-9.

6 "No title," [Online]. Available from: https:// arabdevelopmentportal.com/publication/ egypt-statistical-yearbook-2020-population.

7 El Nahas NM, Shokri HM, Roushdy TM, Aref HM, Hamed SM, Shalash AS, et al. Urban versus rural Egypt: stroke risk factors and clinical profile: cross-sectional observational study. J Stroke Cerebrovasc Dis. 2019;28(11): 104316.
8 Hacke W, Caso V, Esagunde RU, Aref HM, Martina S, Mikulik R. Stroke care taking flight with the wings of ANGELS. A symposium presented by Boehringer Ingelheim at the ESO-WSO Virtual Conference 2020 Nov 8. 2021;6:8-25.

9 "SITS - safe implementation of treatments in stroke". Available from: https://www.sitsinternational.org/about/sits-international-network-organisation/.

10 "ESO and WESO". Available from: https:// www.angels-initiative.com/angels-awards. 